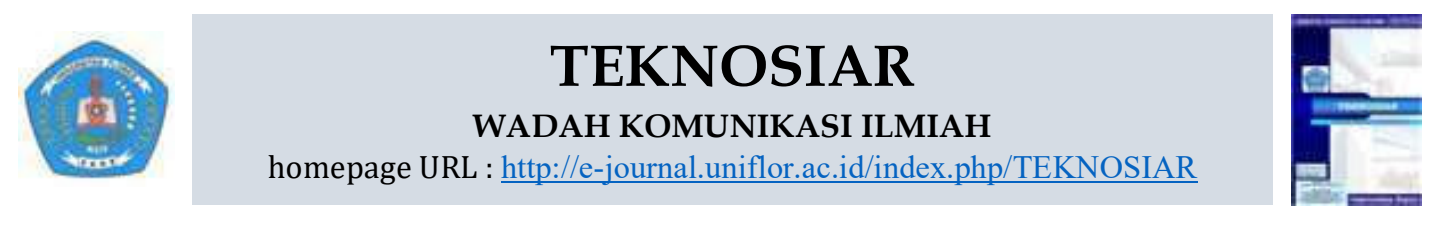

\title{
Pendekatan Arsitektur Vernakular Dalam Desain Fasilitas Obyek Wisata Jasmani - Rohani Mengeruda di Kecamatan Soa Kabupaten Ngada
}

\author{
Gusti Rato ${ }^{1}$, *Petrus Jhon Alfred Depa Dede ${ }^{2}$, Fabiola T.A. Kerong ${ }^{3}$ \\ ${ }^{1}$ Alumni Program Studi Arsitektur Fakultas Teknik Universitas Flores, Ende \\ ${ }^{2,3}$ Dosen Program Studi Arsitektur Fakultas Teknik Universitas Flores, Ende \\ *) Correspondence e-mail: ff3redo@gmail.com
}

Received: 22-03-2021 Revised: 15-04-2021 Accepted: 20-04-2021

\begin{abstract}
Ngada Regency is one of the regencies that has a lot of tourism potential that is able to attract tourists both at home and abroad who want to travel both physically and spiritually. One of them is the Mengeruda PhysicalSpiritual Tourism Object, which is managed by the Ngada Regency Government, in collaboration with Salip Suci Parish, Soa. This tourist attraction is located $28 \mathrm{~km}$ to the east from the center of Bajawa City, precisely in Mengeruda Village, Soa District, Ngada Regency. Physical Tourism Object - Spiritual Mengeruda has 2 (two) mainstay factors, namely Natural Hot Springs and Fatima Park, which are places of pilgrimage for Catholics. However, there are several problems that make this tourism object not optimal, such as: lack of maintenance on existing facilities, lack of main facilities, and supporting facilities to support the image of this tourism object. The reason for choosing the theme with the Vernacular Architecture approach in the design of the Mengeruda Physical-Spiritual Tourism area is because it is located in a community environment that is rich in culture and tradition both in terms of architecture and social life. The method of data collection is done by; literature study, interview, and observation. From the data collected, analysis was carried out. The method of data analysis is done by; quantitative analysis, qualitative analysis, and comparative, After conducting the analysis, the next step is to develop a planning and design concept in accordance with the output and analysis that has been carried out. The results of the design with a vernacular architectural approach can make this tourist spot not only a place of recreation, but also as a medium of learning or introducing culture to tourists at large by showing / highlighting the cultural identity of the community, and can provide an educational impact for tourists
\end{abstract}

Keywords: vernacular architecture, tourism site, spiritual body, soa sub-district

\begin{abstract}
ABSTRAK
Kabupaten Ngada adalah salah satu Kabupaten yang memiliki banyak sekali potensi wisata yang mampu menarik minat wisatawan baik dalam maupun luar negri yang ingin berwisata baik untuk jasmani maupun rohani. Salah satunya yaitu "Obyek Wisata Jasmani-Rohani Mengeruda”, yang dikelola oleh Pemerintah Kabupaten Ngada, bekerja sama dengan Paroki Salip Suci, Soa. Obyek wisata ini berada 28 km ke arah timur dari pusat Kota Bajawa tepatnya di Desa Mengeruda Kecamatan Soa Kabupaten Ngada. Obyek Wisata Jasmani - Rohani Mengeruda memiliki 2 (dua) faktor andalan, yaitu Sumber Mata Air Panas Alam (Hoot Sprin) dan Taman Fatima (Place Of Pilgrimage) yaitu tempat Ziarah bagi Umat ber-agama Katolik. Namun ada beberapa permasalahan yang membuat obyek wisata ini tidak terlalu optimal, seperti: kurangnya perawatan terhadap fasilitas-fasilitas yang sudah ada, kurangnya fasilitas fasilitas utama, dan penunjang sebagai pendukung citra dari obyek wisata ini. Alasan pemilihan tema dengan pendekatan Arsitektur Vernakuler dalam desain kawasan Wisata Jasmani-Rohani Mengeruda ini karena berada dalam lingkungan masyarakat yang kaya akan budaya dan tradisi baik dari segi arsitektural maupun kehidupan sosialnya.
\end{abstract}

TEKNOSIAR Volume 15, No.01, April 2021

p-ISSN 1907-5197 (versi cetak) e-ISSN 2721-2270 (versi online) 
Metode pengumpulan data dilakukan dengan cara; studi literatur, wawancara, dan observasi. Dari data yang dikumpulkan dilakukan analisis. Metode analisis data dilakukan dengan; analisa kuantitatif, analisa kualitatif, dan komparatif, Setelah melakukan analisis, tahap selanjutnya adalah menyusun konsep perencanaan dan perancangan sesuai dengan output dan analisis yang telah dilkakukan. Hasil perancangan dengan pendekatan arsitektur vernakuler dapat menjadikan tempat wisata ini bukan hanya dijadikan tempat rekreasi semata, tetapi juga sebagai media pembelajaran atau mengenalkan budaya ke wisatawan luas dengan cara menunjukan/menonjolkan identitas kebudayaan masyarakatnya, dan dapat memberikan dampak edukatif bagi wisatawan.

Kata kunci: arsitektur vernacular, obyek wisata, jasmani rohani, mengeruda kecamatan soa

\section{PENDAHULUAN}

Dalam kehidupan jasmani, manusia belajar dan berusaha menjaga kesehatanya, supaya tetap dalam keadaan fit untuk meningkatkan kemampuan kerja sehingga dapat melaksanakan tugastugasnya secara optimal untuk mendapatkan hasil yang lebih baik. Sedangkan dalam kehidupan rohani, manusia belajar untuk berinteraksi dengan alam maupun dengan lingkungan sekitar untuk menciptakan kenyamanan, ketentraman yang lebih mengarah kebatiniah dan terkadang mengarah kepada apa yang diyakini atau di percaya. Oleh karena itu perlu adanya suatu wadah atau kawasan wisata yang dapat menampung kegiatan Jasmani dan Rohani agar sejalan dan seimbang.

Kabupaten Ngada adalah salah satu Kabupaten yang bisa memberikan solusi, atau mampu menyediakan kebutuhan bagi wisatawan yang ingin berwisata baik untuk jasmani maupun rohani. Hal tersebut cukup beralasan mengingat daerah ini memiliki banyak sekali potensi wisata yang mampu menarik minat wisatawan baik dalam maupun luar negri. Obyek wisata yang mampu memberikan solusi, atau mampu menyediakan kebutuhan bagi wisatawan baik jasmani maupun rohani, yaitu "Obyek Wisata Jasmani-Rohani Mengeruda", yang dikelola oleh Pemerintah Kabupaten Ngada, bekerja sama dengan Paroki Salip Suci, Soa. Obyek wisata ini berada $28 \mathrm{~km}$ ke arah timur dari pusat Kota Bajawa tepatnya di Desa Mengeruda Kecamatan Soa Kabupaten Ngada.

Obyek Wisata Jasmani - Rohani Mengeruda memiliki 2 (dua) faktor andalan, yaitu Sumber Mata Air Panas Alam (Hoot Sprin) dan Taman Fatima (Place Of Pilgrimage) yaitu tempat Ziarah bagi Umat ber-agama Katolik. Faktor-faktor andalan tersebut walaupun masih dalam satu lokasi tetapi dibatasi oleh tembok pembatas, sehingga wisatawan yang berkunjung, baik ke Air Panas maupun ke Taman Fatima tidak merasa saling terganggu. Obyek wisata Jamani-Rohani Mengeruda ini memiliki faktor-faktor pendukung istiewa seperti; udara yang masih sejuk, memiliki best view dari dalam maupun luar tapak, telah tersedia fasilitas-fasilitas pendukung dan sarana dan prasarana yang baik. Sarana pada kawasan obyek wisata ini berupa sarana penunjang berupa sistem transportasi ke kawasan yang memadai, baik jalur darat maupun udara sedangkan prasarana beruapa sistem utilitas pada kawasan seperti air bersih dan listrik sudah memadai.

Namun ada beberapa kendala atau permasalahan yang membuat pudarnya citra obyek wisata ini sehingga menjadi tidak terlalu optimal, seperti: kurangnya perawatan terhadap fasilitas-fasilitas yang sudah ada dan cendrung dibiarkan apa adanya, dan kurangnya fasilitas fasilitas utama, penunjang dan khusus yang memadai sebagai pendukung citra dari obyek wisata, padahal obyek wisata ini bukan hanya dikunjungi Wisatawan Lokal tetapi juga wisatawan mancanegara. Dengan melihat permasalahan tersebut, maka perlu penataan kembali fasilitas Obyek Wisata Jasmani-Rohani Megeruda tersebut.

Pemilihan tema dengan pendekatan Arsitektur Vernakuler dalam desain kawasan Wisata Jasmani-Rohani Mengeruda ini cukup beralasan karena berada dalam lingkungan masyarakat yang kaya akan budaya dan tradisi baik dari segi arsitektural maupun kehidupan sosialnya. Selain itu untuk mengantisipasi akibat negative yang mungkin akan timbul, terutama yang disebabkan oleh komersialisasi berlebihan yang dihadirkan oleh para wisatawan. Dengan pendekatan arsitektur vernakuler, masyarakat Kabupaten Ngada bisa lebih menyadari dan menghargai kekayaan budayanya sendiri dan menjadikan tempat wisata ini bukan hanya dijadikan tempat rekreasi semata, tetapi juga sebagai media pembelajaran atau mengenalkan budaya ke wisatawan luas dengan cara

TEKNOSIAR Volume 15, No.01, April 2021

p-ISSN 1907-5197 (versi cetak) e-ISSN 2721-2270 (versi online) 
menunjukan/menonjolkan identitas kebudayaan masyarakatnya, dalam arti kata lain obyek wisata tersebut dapat memberikan dampak edukatif bagi wisatawan.

\section{Wisata Jasmani dan Rohani}

Wisata jasmani yaitu wisata yang bertujuan untuk memberikan kepuasan kepada wisatawan dan bersifat aktif, dan dapat dirasakan dampaknya secara langsung, baik itu di lihat dan di pegang, dalam arti kata lain wisatawan dapat langsung ikut berperan aktif dalam kegiatan-kegiatan yang ditawarkan dalam wisata tersebut. Wisata rohani yaitu wisata yang bertujuan untuk memberikan kepuasan kepada wisatawan dan lebih mengarah keperasaan yang dirasakan (batin) dan tidak dapat dilihat ataupun dipegang secara langsung, dan wisata-wisata lain yang memberikan kepuasan kepada wisatawan dengan cara berinteraksi dengan alam dan lingkungan sekitar untuk menciptakan kenyamanan dan ketentraman. Dan contoh wisata rohani, seperti; wisata pilgrim karena jenis wisata ini dikaitkn dengan agama, kepercayaan, ataupun adat istiadat di dalam masyarakat.

Inti utama kegiatan wisata jasmani-rohani yaitu sama seperti inti utama kegiatan wisata lainya, yaitu sebuah penyegaran yang sehat dan wajar yang mampu memberikan suasana baru (enthuasiasme) misalnya dengan bersantai, bermain dalam hal batiniah dan juga badaniah (raga) yaitu dengan berolah raga, menikmati pemandangan alam dan juga melakukan kontak sosial. (Karyono, 1997:14). Ketetapan MPRS No. 1 Tahun 1960 (Yoeti :118) kepariwisatan dalam dunia modern pada hakekatnya adalah suatu cara untuk memenuhi kebutuhan manusia dalam memberi liburan rohani dan jasmani setelah beberapa waktu bekerja serta mempunyai modal untuk melihatlihat daerah lain (pariwisata dalam negri) atau negara lain (pariwisata luar negri).

\section{Arsitektur Vernakular}

Kata vernakular berasal dari bahasa latin, Vernaculus, yang berarti asli (Native). Maka vernakular arsitektur diartikan sebagai arsitektur asli yang dibangun oleh masyarakat setempat. Menurut Paul Oliver dalam bukunya Ensiklopedia Arsitektur Vernakular menjabarkan bahwa arsitektur vernakuler, konteks dengan lingkungan sumber daya setempat yang dibangun oleh suatu masyarakat dengan menggunakan teknologi sederhana untuk memenuhi kebutuhan karakteristik yang mengakomodasi nilai ekonomi dan tatanan budaya dari masyarakat tersebut, serta dibangun oleh tukang berdasarkan pengalaman (trial and error), menggunakan teknik dan material lokal serta merupakan jawaban atas setting lingkungan tempat bangunan tersebut berada dan selalu membuka untuk terjadinya transformasi.

Setiap wilayah memiliki ciri arsitektur yang spesifik dan berasal dari tradisi, antara tradisi dan arsitektur vernakular sangat erat hubungannya. Tradisi memberikan suatu jaminan untuk melanjutkan kontinuitas akan tatanan sebuah arsitektur melalui sistem persepsi ruang, bentuk, dan konstruksi yang dipahami sebagai suatu warisan yang akan mengalami perubahan secara perlahan melalui suatu kebiasaan, Misalnya bagaimana adaptasi masyarakat lokal terhadap alam, yang memunculkan berbagai cara untuk menanggulangi, misalnya iklim dengan cara membuat suatu tempat bernaung untuk menghadapi iklim dan menyesuaikannya dengan lingkungan sekitar dan dengan memperhatikan potensi lokal seperti potensi udara, tanaman, material alam dan sebagainya, maka akan terciptalah suatu bangunan arsitektur rakyat yang menggunakan teknologi sederhana dan tepat guna. Kesederhanaan inilah yang merupakan nilai lebih sehingga tercipta bentuk khas dari arsitektur vernakular dan tradisional serta menunjukkan bagaimana menggunakan material secara wajar dan tidak berlebihan. Hasil karya rakyat ini merefleksikan akan suatu masyarakat yang akrab dengan alamnya, kepercayaannya, dan norma-normanya dengan bijaksana (Oliver, 1997).

\section{Arsitektur Vernakuler Kabupaten Ngada}

Ada beberapa seni arsitektur dan tradisi budaya kabupaten Ngada yang bisa digunakan/diterapakan kedalam konsep perencanan obyek wisata tersebut, antara lain:

TEKNOSIAR Volume 15, No.01, April 2021

p-ISSN 1907-5197 (versi cetak) e-ISSN 2721-2270 (versi online) 
1. Pola perkampungan

Pada umumnya pola perkampungan adat yang berada di kabupaten Ngada menggunakan pola persegi, dan rumah adat semuanya mengarah ketengah kampong/ kisa nata. Kisa nata merupakan tempat yang letaknya berada dalam tengah kampung, yang merupahkan tempat inti kegiatan yang akan dilangsungkan atau di adakan oleh masyarakat setempat, seperti pesta adat atau keiatankeiatan lainya.

2. Rumah adat (Sa'o)

a. Pengguanaan sistem kolom

Rumah adat Suku Bajawa ( $\mathrm{Sa}$ ”) pada dasarnya sama seperti rumah adat lainya di daratan Flores, yaitu meggunakan material alam sebagai bahan konstruksi. Rumah adat suku bajawa merupakan rumah kolong/bangunan yang di buat tidak langsung ditempatkan ditanah melainkan menggunakan beberapa tiang penyangga sebagai penahan rumah tersebut. rumah kolong dibuat karena untuk menyesuaikan dengan iklim setempat, yaitu iklim tropis yang berfungsi untuk mengurangi pengerasan pada tapak.

b. Denah rumah adat

Nenek Moyang Suku Bajawa sudah mengenal sistem perzoningan sejak dulu, hal tersebut diperkuat dengan denah rumah adat Bajawa yang telah memakai system perzoningan. Denah Rumah Adat Suku Bajawa dapat di jelaskan sebagai berikut; Teda (Zona Public) adalah ruang terbuka dimana biasa di gunakan oleh penghuni rumah adat tersebut maupun masyarakat sekitar sbagai teras. Teda One (Zona Semi Private) adalah ruangan tengah yang biasa di gunakan sebagai ruang tamu untuk memerima tamu yang datang untuk membicarakan hal-hal yang bersifat sedikit privasi. One (zona Private) adalah ruang utama atau inti dari bangunan rumah adat tersebut. Ruangan ini biasa dipakai sebagi ruang tidur dan dapur oleh penghuni rumah tersebut dan apabila ada acara-acara adat hanya boleh dipakai oleh tua-tua adat dan anggota suku dari rumah adat tersebut.

3. Filosofi

a. Pintu rumah adat. Pintu rumah adat suku bajawa khususnya dari teda au ke one memiliki tinggi hanya $130 \mathrm{~cm}$ dalam arti tidak memiliki tinggi standar pada umumnya pintu rumah. Hal tersebut beralasan karena Suku Bajawa berkeyakinan bahwa setiap rumah adat (sao) memiliki jiwa, karena rumah tersebut bukan hanya rumah biasa tetapi juga sebagai tempat tinggal nenek moyang, sehingga siapapun yang akan masuk kedalam inti rumah adat (sao) dengan sendirinya akan tunduk untuk menghormati leluhur atau nenek moyang yang berada dalam rumah tersebut.

b. Tradisi kago wana. Masyarakat suku Bajawa pada umumnya berkeyakinan bahwa segala sesuatu yang dilakukan berawalan dari kanan (kago wana) di anggap memberikan dampak yang positif/baik. Kebiasaan tersebut dapat kita jumpai pada saat acara makan bersama (meghe), orang yang membagi makan atau minum harus mendahului orang yang posisi duduk sebelah kanan dari posisi dia masuk atau duduk. Hal lain yang dapat kita jumpai pola kebiasaan seperti itu juga pada saat mengerjakan rumah yang menggunakan material kayu/bambu dan menari adat $\left(j a^{\prime} i\right)$, pada saat mengerjakan rumah yang harus dilakukakn yaitu pada saat pemasangan lat / regel, pangkal kayu ( $p u$ " $u$ ) harus mengarah kekanan telebih dahulu setelah itu baru system selang-seling, dan menari adat $\left(j a^{\prime} i\right)$ pada saat ritual adat kita harus memutar haluan kekanan.

4. Peninggalan yang diyakini

Wai Oba merupakan cerita adat yang sering diceritakan secara turun temurun dan diyakini kebenaranya karena memiliki bukti nyata dan pnjelasan yang logis. Wai Oba terdiri dari 2 suku kata, yakni Wai (kaki) dan Oba (nama orang).

5. Simbol adat

Simbol adat merupakan lambang perwajahan leluhur, yang mana terdapat pada suatu Nua atau perkampungan. symbol adat ini di buat, dibangun, dan ditempatkan di tengan kampung atau nua, yang berhadapan langsung dengan rumah adat atau $s a^{\prime} o$. symbol adat ini terdiri dari:

TEKNOSIAR Volume 15, No.01, April 2021

p-ISSN 1907-5197 (versi cetak) e-ISSN 2721-2270 (versi online) 
a. Madhu, merupakan strukur bangunan pelengkap berbentuk payung yang berada dalam kampung tradisional Suku Bajawa, yang melambangkan nenek moyang laki-laki.struktur madu terdiri dari satu batang kayu yang berdiameter $20-30 \mathrm{~cm}$ sebagai tiang utama dan diatsnya ditambah dengan sruktur bambu utuh yang di belah dan dirangkai sedemkian rupa untuk menjadi rangka atap (Ghubu Madhu). Dalam penerapan arsitektur saat ini madhu bisa di jadikan atau ditransformasikan untuk menjadi bangunan pelengkap pada taman atau pada daerah-daerah obyek wisata lainya sebaggai tempat istirahat atau lopo.

b. Bhaga, merupakan struktur bangunan pelengkap yang simbolnya kebalikan dari madhu (nenek moyang perempuan) dan berada di tengah kampung juga. Struktur bhaga terbuat dari beberapa lembar papan dan 4 tiang utama yang di bentuk menjadi kubus dan dilengkapi dengan pintu masuk dan struktur atap terbuat dari beberapa batang bambu dan bila bambu yang diikat dengan tali ijuk tampa mengunakan paku.

c. Kaba pere, merupakan symbol adat yang terdapat dalam rumah adat sebagai pijakan pada pintu masuk dari teda one ke one.

d. Ukiran-ukiran adat. Ukiran adat suku bajawa berupa hasil pahatan kaligrafi pada dinding rumah adat, madhu dan bhaga yang mempunyai nilai filosofinya masing- masing.

\section{METODE}

Metode pengumpulan data dilakukan dengan cara sebagai berikut; 1). studi literatur, mempelajari teori-teori yang bersumber dari buku-buku, majalah, dan artikel. 2). wawancara, dengan orang yang berkompeten guna memperoleh data yang akurat. 3). observasi, melakukan pengamatan secara langsung terhadap objek dan lokasi penelitian. Hasil pengamatan berupa; a). kondisi fisik lapangan yang meliputi topografi, batasan site, pencapaian lokasi, lad use, kelayakan obyek. b). kondisi geogreafis meliputi data suhu, iklim, angin, kelembapan udara dan data yang mendukung perencanaan. c). kondisi site meliputi sirkulasi kendaraan, sirkulasi manusia dan sarana prasarana yang mendukung. d). pengamatan lingkungan meliputi aktivitas masyarakat sekitar misalnya pengunjung maupun pengguna lain yang beraktivitas di sekitar site.

Dalam melakukan penelitian ini, metode analisis data dilakukan dengan; 1). analisa kuantitatif, membuat perhitungan tertentu berdasarkan standar untuk pemenuhan kebutuhan dan dimensi ruang. 2). analisa kualitatif, penciptaan suasana dan karakter tampilan (proporsi bangunan, warna, tekstur, dan elemen dekoratif). 3). komparatif, metode yang digunakan untuk melakukan perbandingan dengan proyek sejenis. Setelah melakukan analisis, tahap selanjutnya adalah menyusun konsep perencanaan dan perancangan sesuai dengan output dan analisis yang telah dilkakukan.

\section{HASIL DAN PEMBAHASAN}

\section{Konsep Arsitektur Vernakuler}

Konsep tampilan arsitektur vernakuler yang dipakai pada kawasan obyek wisata jasmani-rohani Mengeruda ini berfariasi, mulai dari penerapan filosofi/ tradisi yang biasa dipakai dalam kehidupan sehari-hari, cerita rakyat sampai pada bentuk-bentuk simbol adat serta bahan material lokal.

1. Konsep Filosofi/ Tradisi Kago Wana

Konsep dari ME dan SE mengunakan filosofi / tradisi yang biasa dilakukan dalam keidupan sehari-hari masyarakat suku Bajawa, yaitu kago wana. Dari filosofi / tradisi kebudayaan suku Bajawa diatas dapat kita transformasikan kedalam konsep jalan masuk dan keluar kawasan obyek wisata jasmani-rohani Mengeruda, yaitu jalan masuk kelokasi kawasan menggunakan jalur, kanan dalam arti kata lain tidak mengikuti aturan rambu lalu lintas Indonesia. Hal tersebut didukung dengan perencanaan tempat parkir pengunjung yan terletak sebelah kanan dari pintu masuk dalam kawasan wisata jasmani-rohani Mengeruda.

TEKNOSIAR Volume 15, No.01, April 2021

p-ISSN 1907-5197 (versi cetak) e-ISSN 2721-2270 (versi online) 


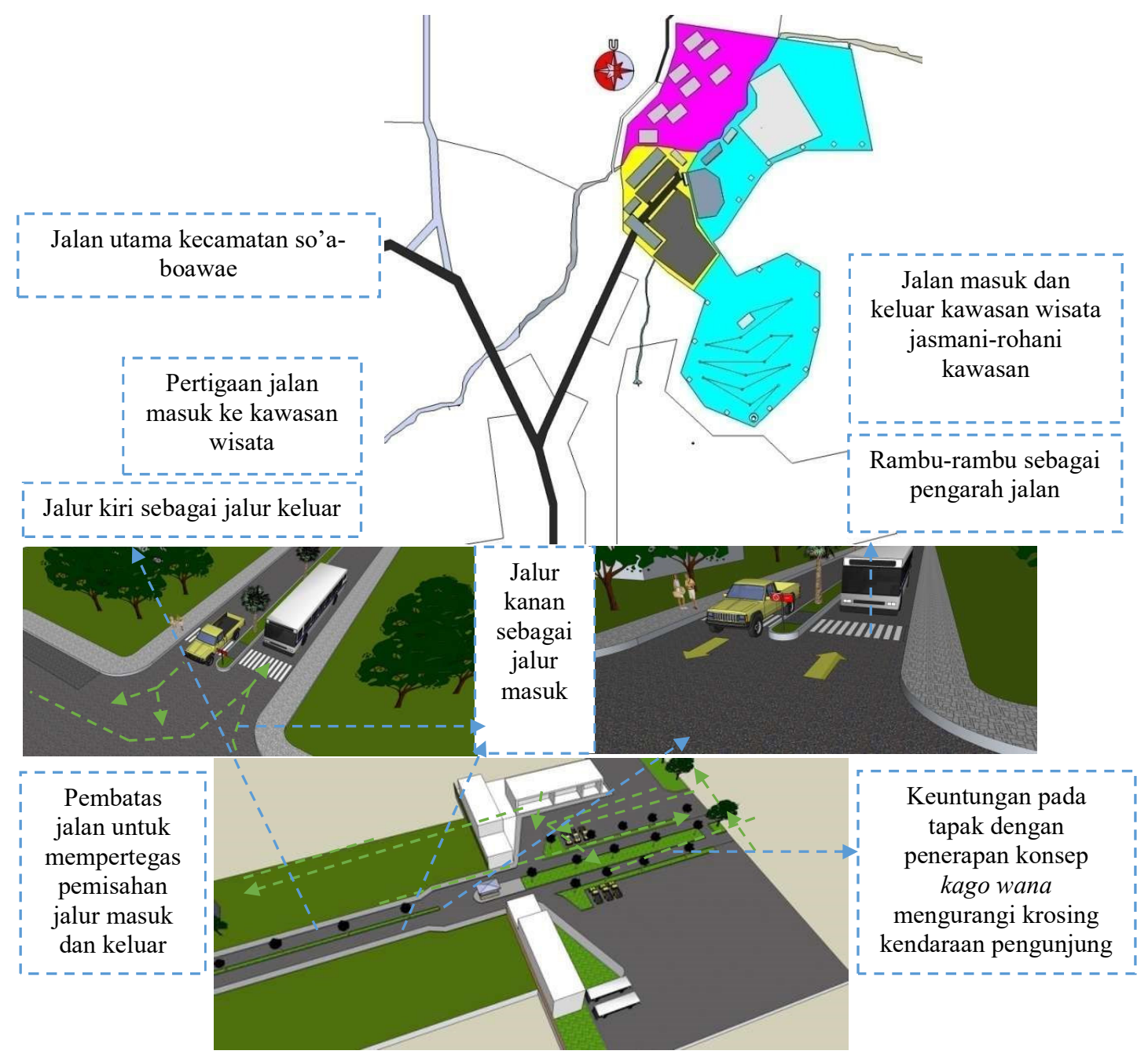

Gambar 1. Penerapan konsep kago wana pada jalan masuk dan keluar ( $M E$ dan $S E$ )

Sumber: analisa pribadi

Pada jalur sirkulasi kendaraan menggunakan konsep kago wana, pada pintu masuk dari zona public menuju ke zona semi public maupun zona prifat menggunakan konsep filosofi pintu pendek, sehingga bisa menimbulkan pertanyaan atu rasa ingin tahu pengunjung atau wisatawan.

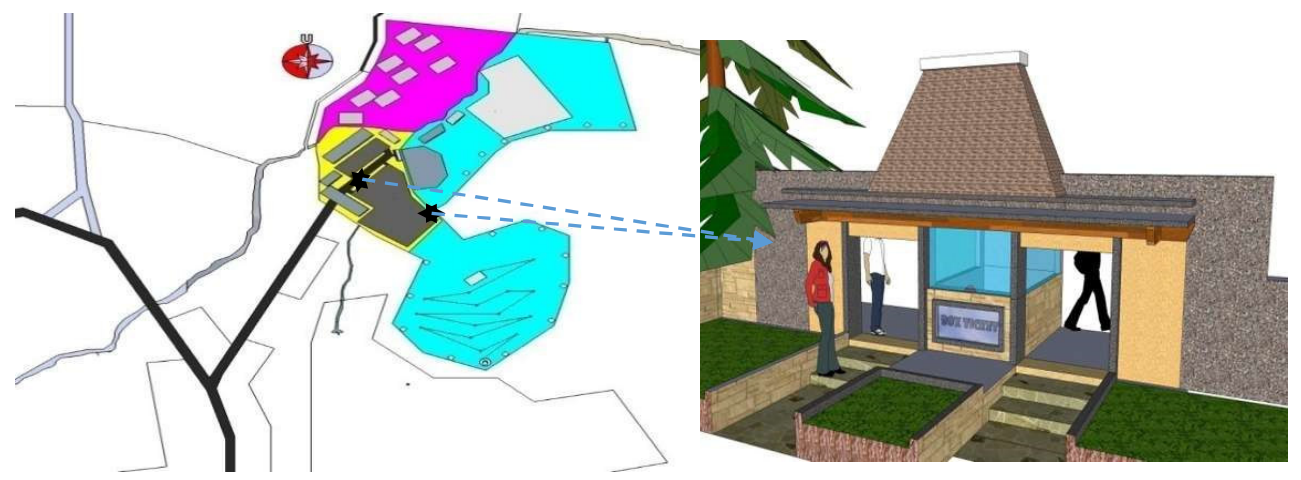

Gambar 2. Penerapan konsep pintu pendek Sumber: analisa pribadi

TEKNOSIAR Volume 15, No.01, April 2021

p-ISSN 1907-5197 (versi cetak) e-ISSN 2721-2270 (versi online) 


\section{Konsep Simbol Adat (Kaba Pere)}

Tampilan maupun denah ruang pengelola mengambil konsep dari tampilan simbol adat, yaitu kaba pere. Kaba pere merupakan simbol adat suku bajawa yang terletak dalam rumah adat sebagai pijakan kaki sebelum masuk kedalam inti rumah adat (on'e).

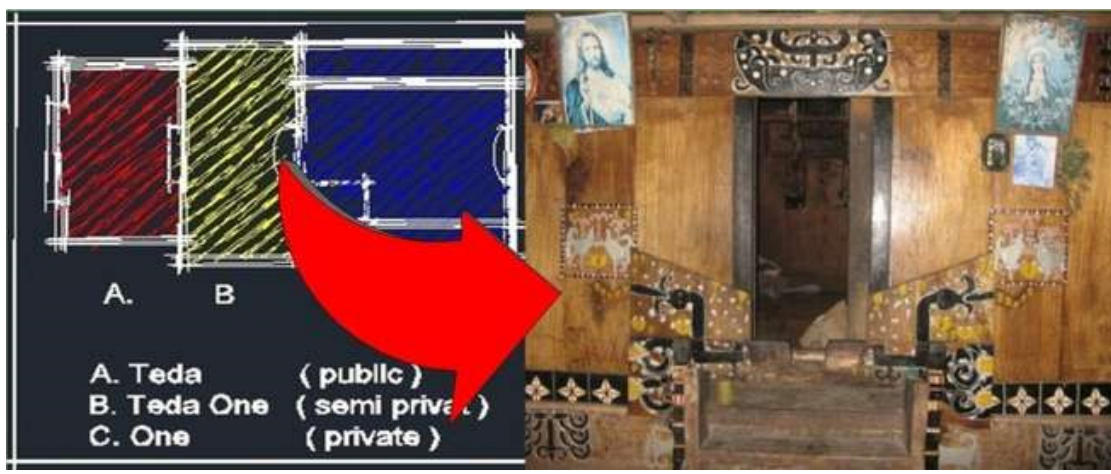

Gambar 3. Letak kaba pere dalam rumah adat Sumber: analisa pribadi

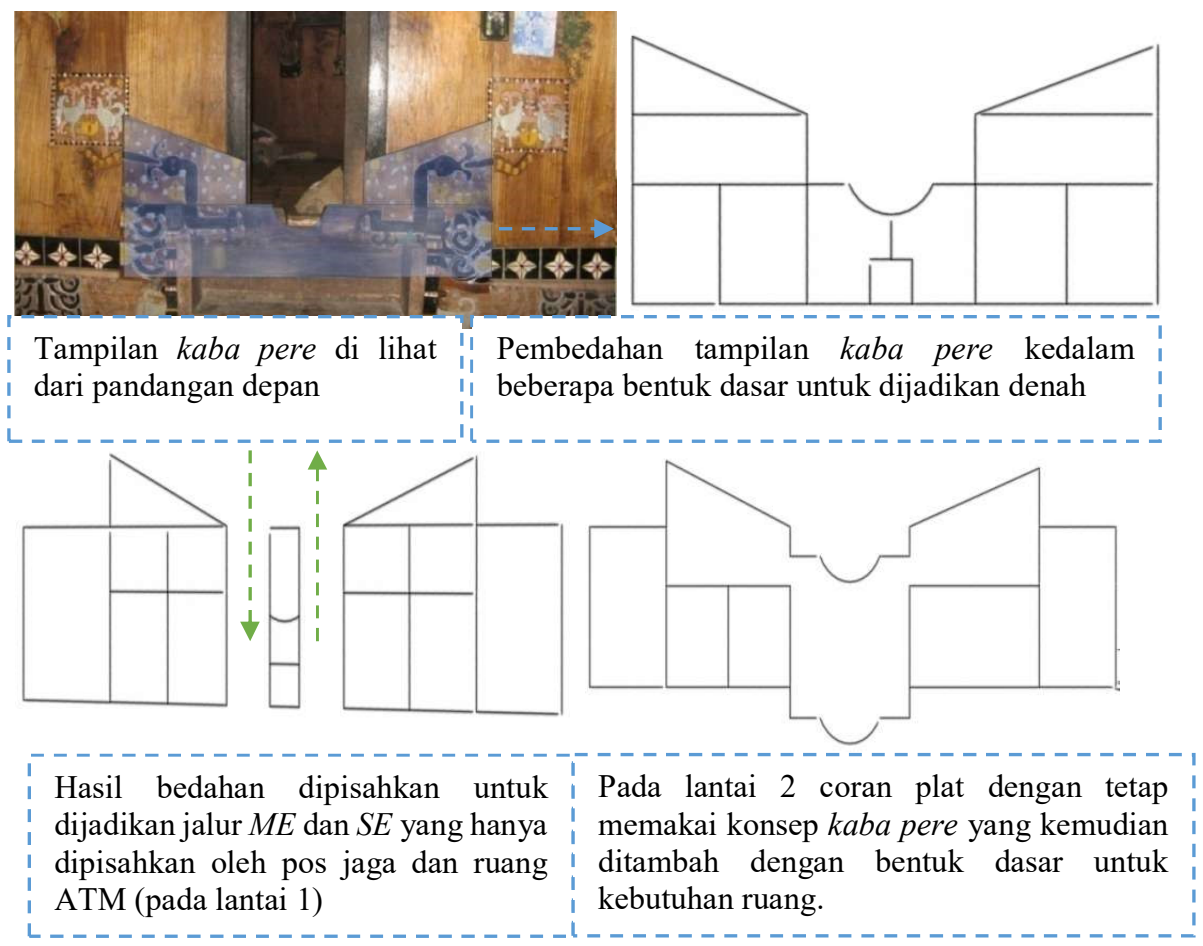

Gambar 4. Konsep denah pengelola Sumber: analisa pribadi 

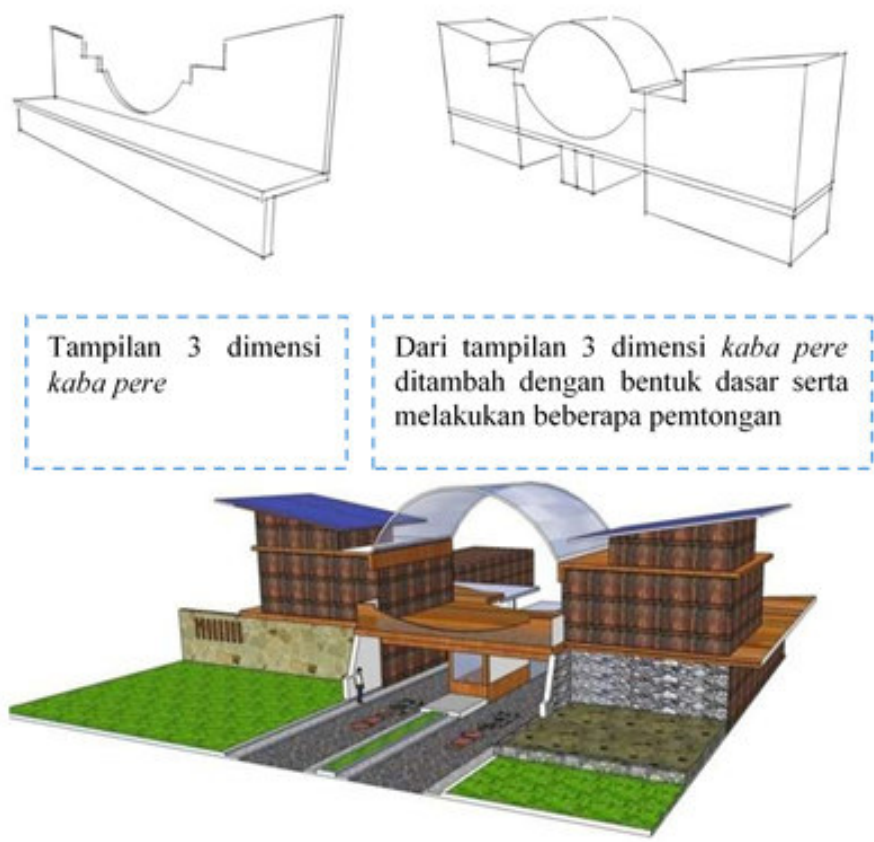

Gambar 5. Konsep tampilan bangunan pengelola Sumber: analisa pribadi

3. Konsep symbol adat Ngadhu dan Bhaga / symbol perwajahan leluhur perempuan dan laki-laki. Konsep symbol adat Ngadhu dan Bhaga dapat kita terapkan pada bangunan altar baik denah maupun tampilanya.

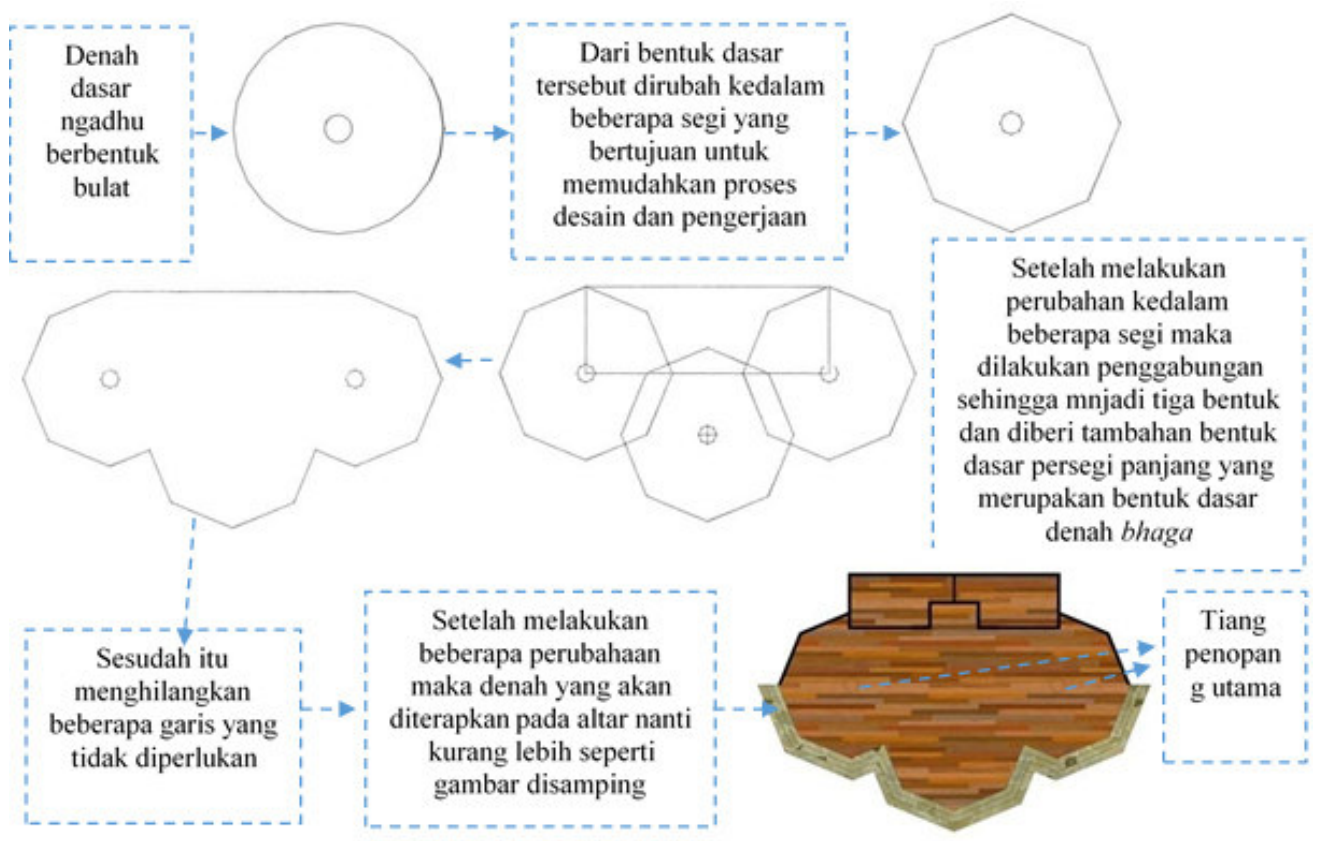

Gambar 6. Konsep penerapan bentuk dasar ngadhu sebagai denah dasar altar Sumber: analisa pribadi

TEKNOSIAR Volume 15, No.01, April 2021

p-ISSN 1907-5197 (versi cetak) e-ISSN 2721-2270 (versi online) 
Untuk tampilan bangunan atap altar juga menggunakan atap Ngadhu yang berbentuk kerucut dan juga Bhaga.

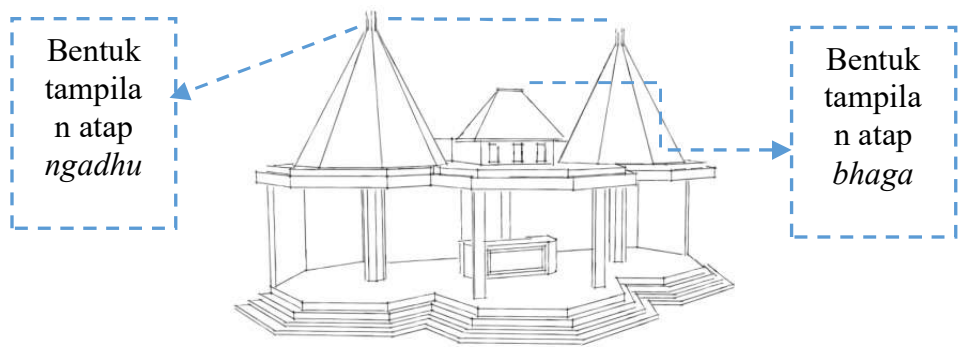

Gambar 7. Konsep atap Ngadhu dan Bhaga pada bangunan altar Sumber: analisa pribadi

\section{Konsep Pola Perkampungan}

Pola perkampungan adat suku Bajawa yang pada umumnya berpola persegi dapat kita terapkan pada denah bangunan restaurant.

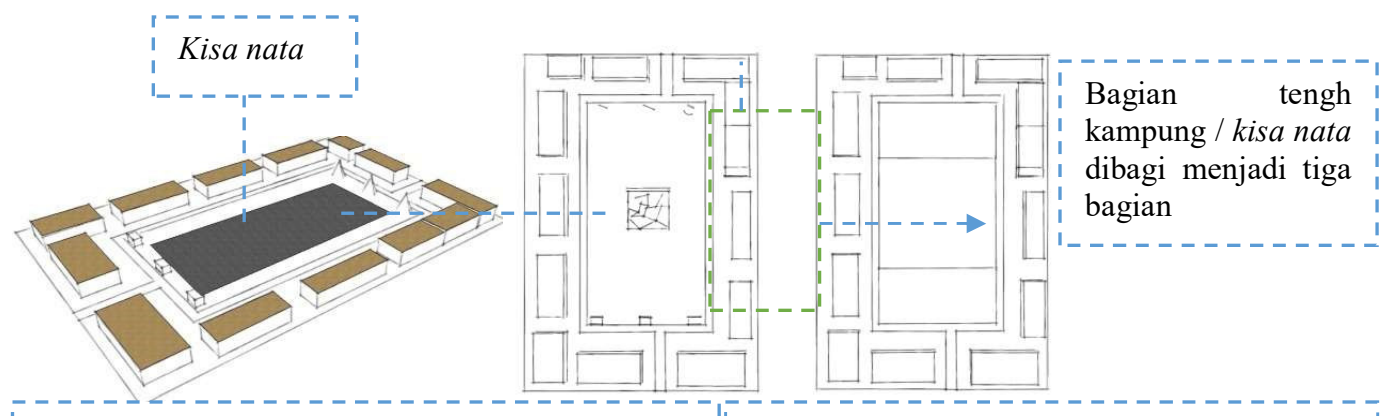

Dari beberapa perubahan dengan permainan garis dari pola perkampungan tersebut mmaka terbentuk denah seperti di bawah ini
Sketsa rumah adat dalam lingkaran kampung tersebut dihilangkan tetapi jalan denah yang merupakan jalan masuk dan keluar kampung dipertahankan

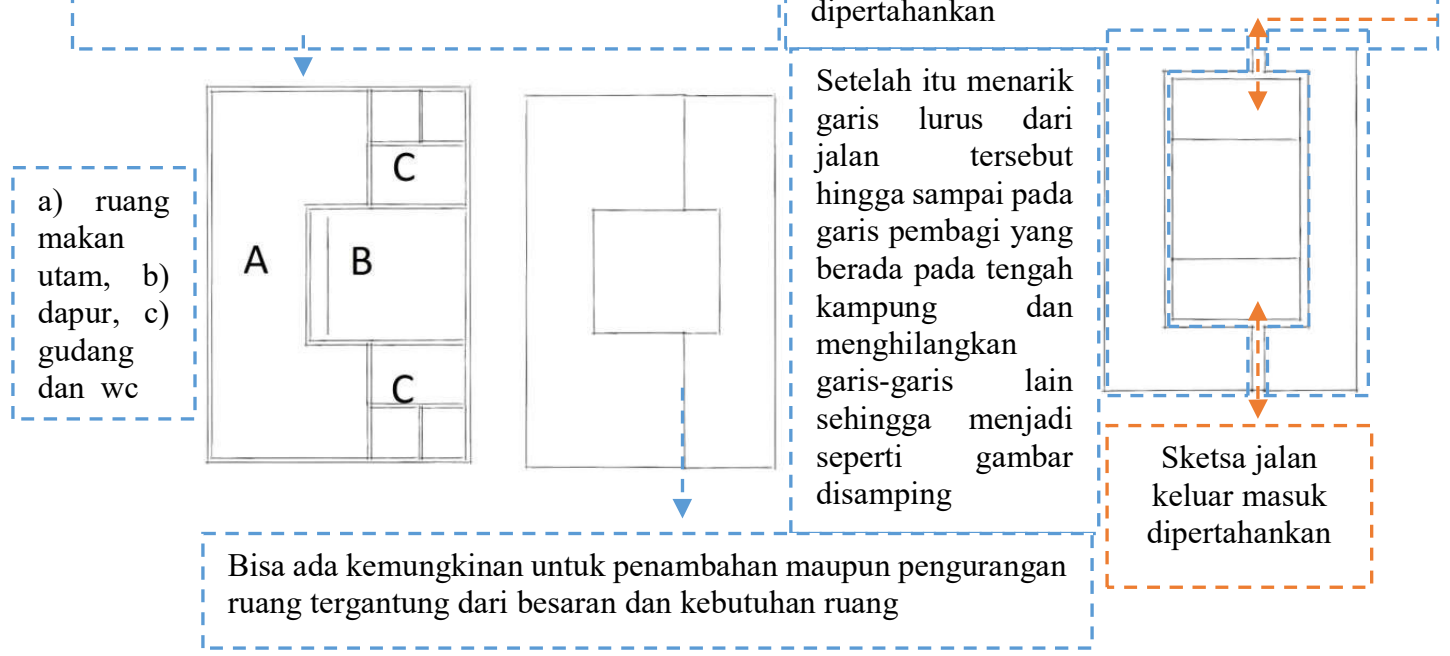

Gambar 8. Konsep denah rumah adat dengan penerapan pola pemukiman kampung adat Sumber: analisa pribadi

TEKNOSIAR Volume 15, No.01, April 2021

p-ISSN 1907-5197 (versi cetak) e-ISSN 2721-2270 (versi online) 
penerapan konsep pola perkampungan adat suku Bajawa pada bangunan restaurant cukup beralasan, karna didalam suatu kampung terdapat Kisa Nata yang merupakan inti dari kampung tersebut atau pusat dari semua kegiatan ritual adat dalam suatu kampung. Sama halnya dengan restaurant, yang menjadi inti dalam suatu restaurant yaitu dapur.

5. Konsep Sistem Kolom

rumah adat suku Bajawa menggunakan system kolom ( $\mathrm{Sa}$ 'o Tolo). Hal tersebut kita dapat terapkan dalam penggunaan struktur bangunan yang berada dalam kawasan wisata, dalam arti kata lain kita dapat menyiasati tanah berkontur dan juga mengurangi daerah pengerasan.
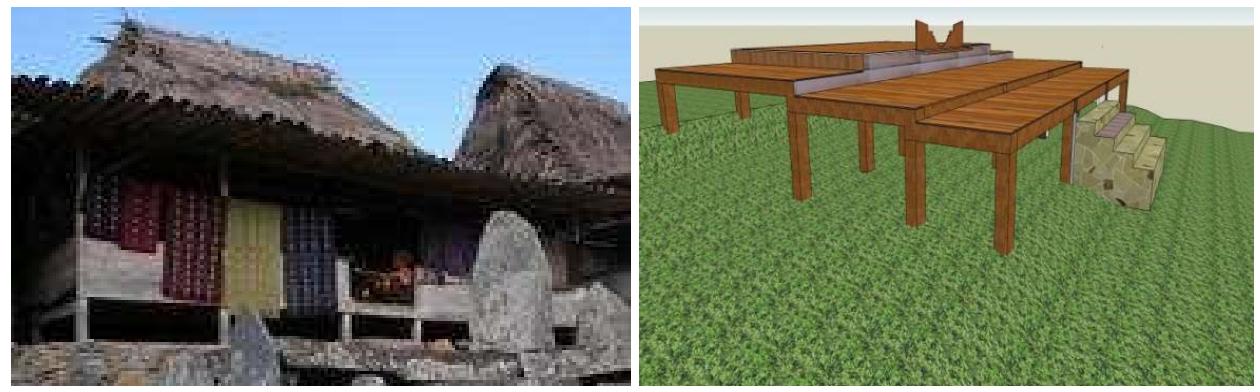

Gambar 9. Penerapan sistem kolom pada rumah adat ( $\mathrm{Sa}$ 'o) Sumber: dokumen dan sketsa pribadi

Denah rumah adat dengan tampilan 3 dimensi yang menggunakan trap dan sistem tiang kolom serta perzoniingan. Bagian Teda One diturunkan sebagian untuk sama rata dengan Teda sehingga membentuk denah dengan pembagian ruan seperti dibawah.

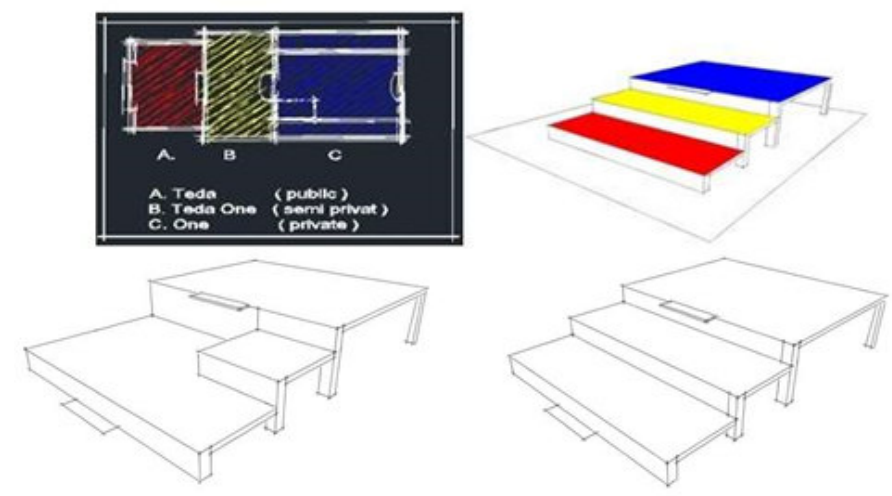

Denah yang telah di transformasikan dari denah rumah adat ditetapkan berdasarkan tingkat keprifasian seperti yan telah di jelaskan pada sistem perzoningan rumah adat suku bajawa

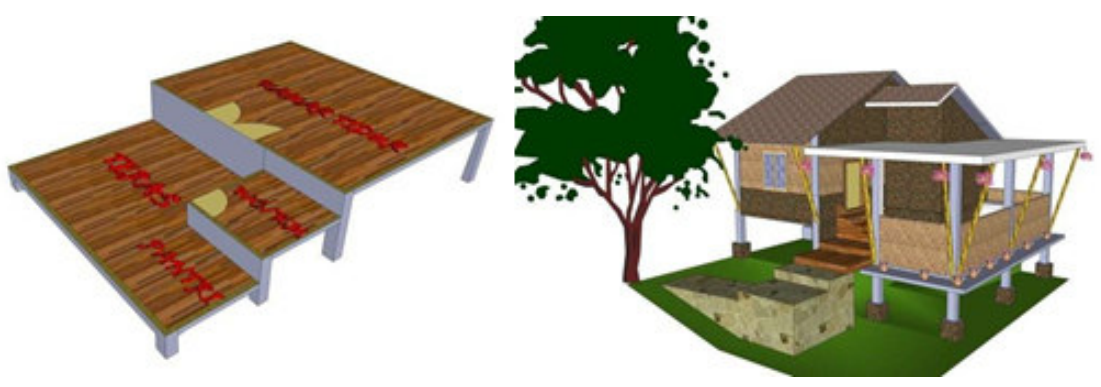

Gambar 10. konsep denah dan tampilan homestay

TEKNOSIAR Volume 15, No.01, April 2021

p-ISSN 1907-5197 (versi cetak) e-ISSN 2721-2270 (versi online) 
6. Konsep Ukiran Adat

Sumber: skertsa pribadi
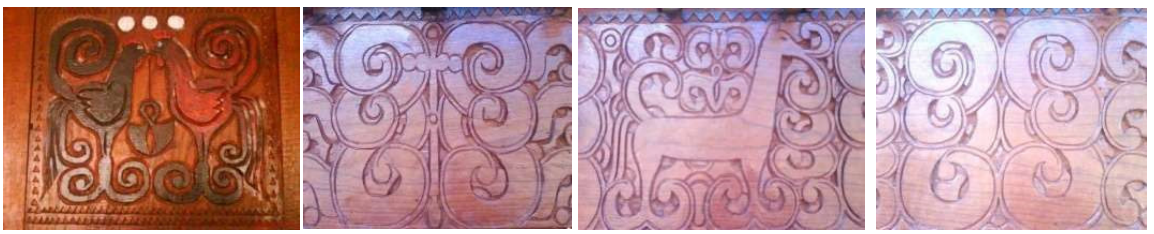

Gambar 11. Ukiran-ukiran adat yang terdapat pada rumah adat maupun pada symbol adat Sumber: dokumentasi pribadi

Ukiran ukiran adat diatas dapat ditransformasikan pada pembuatan ventilasi pada bangunan, sehingga memiliki dua fungsi sekaligus, yakni sebagai lubang penghawaan dan juga untuk menambah nilai estetika dengan menonjolkan arsitektur vernakuler Kabupaten Ngada.


Hasil transformasi

bentuk dari ukiran adat

Gambar 12. Konsep ventilasi menggunakan ukiran adat Sumber: sketsa pribadi

7. Konsep Wai Oba

Konsep Wai $\mathrm{Oba}$ dapat kita terapkan pada kedua kolam renang yang dibedakan antara kolam renang air panas dan air dingin, serta kolam anak yang dipisahkan dari kolam dewasa. Kolam renang anak yang merupakan bagian jari kaki. Transformasi bentuk dari sketsa kedua tlapak kaki (wai oba) untuk memisahkan kolam dewasa dan anak-anak.

TEKNOSIAR Volume 15, No.01, April 2021

p-ISSN 1907-5197 (versi cetak) e-ISSN 2721-2270 (versi online) 


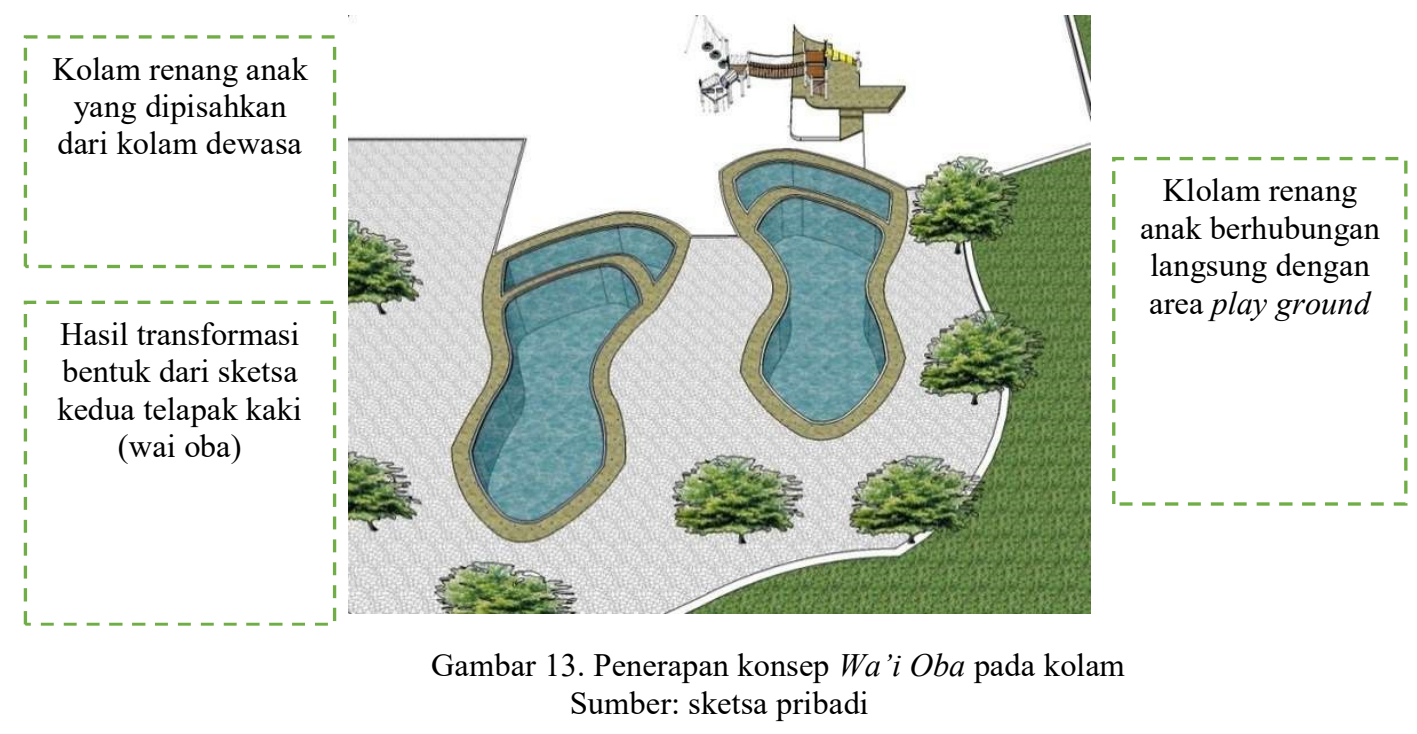

\section{KESIMPULAN}

Konsep penerapan arsitektur vernakuler yang dipakai pada kawasan obyek wisata jasmanirohani Mengeruda ini mulai dari penerapan pola permukiman, filosofi/ tradisi yang biasa dipakai dalam kehidupan sehari-hari, cerita rakyat sampai pada bentuk-bentuk simbol adat serta bahan material lokal. Hasil perancangan dengan pendekatan arsitektur vernakuler dapat menjadikan tempat wisata ini bukan hanya dijadikan tempat rekreasi semata, tetapi juga sebagai media pembelajaran atau mengenalkan budaya ke wisatawan luas dengan cara menunjukan/menonjolkan identitas kebudayaan masyarakatnya dan dapat memberikan dampak edukatif bagi wisatawan.

\section{DAFTAR PUSTAKA}

A Hari Karyono. 1997. Kepariwisataan. Jakarta: PT. Grasindo

Janianton Damanik dan Helmut F. Webber. 2006. Perencanaan Ekowisata Dari Teori ke Aplikasi. Yogyakarta: Andi

Ketetapan MPRS No. 1 Tahun 1960, Tentang Pariwisata

Oka A. Yoeti, Drs, Pengantar Ilmu Pariwisata, 1985

Paul Oliver, Encyclopedia of Vernacular Architecture of the World

Prof. Hunziger dan Kraf dari swiss dari tahun 1942 (dalam Yoeti, 1996)

Profil Desa Mengeruda (dalam angka 2013)

Samsuridjal D dan Kaelany H.D. 1997. Peluang Dibidang Pariwisata. Jakarta: PT. Pradnya Paramitha

UU RI. No. 9 Th 1990 tentang Kepariwisataan

Vale, Brenda, dan Robert. 1991. Vernacular Architecture, London

TEKNOSIAR Volume 15, No.01, April 2021

p-ISSN 1907-5197 (versi cetak) e-ISSN 2721-2270 (versi online) 